\title{
Organizational Culture and Employee Satisfaction: An Exploratory Study
}

\author{
Xiaoxia Zhang and Bing Li
}

\begin{abstract}
Organizational culture has been considered as one of important core competencies of an organization. The individuals, groups and the organization as a whole are running under its culture although it is almost intangible. This paper attempts to describe organizational culture and to explore the relationship between organizational culture and employee satisfaction under the case of a Chinese family firm. As a side product, a quantitative approach is provided to support managerial decisions on culture changes in order to improve organizational effectiveness.
\end{abstract}

Index Terms-Organizational culture, employee satisfaction, family firm, Chinese situation.

\section{INTRODUCTION}

Organizational culture has been received extraordinary attention ever since the concept was proposed by American scholars in 1980's. By contrast with the management practice in Japanese companies, the concept of organizational culture was proposed and related theories were developed. The academia and managerial practitioners have reached the consensus that organizational culture is the core competency for an organization. It will impact effectiveness or performance of the individuals, the groups and the whole organization.

Employee satisfaction reflects the psychological state of the individuals working in an organization. Although it is implicit, it will obviously impact the employee's performance. Organizational culture can have an influence on employee satisfaction. The relationship between them should be clarified in order to provide managerial practitioners with more meaningful guidance to their practices.

With the development of Chinese economy, the managerial problems of specific situations in China are attracting much more concerns. Under the case study of a Chinese family firm, this paper attempts to quantitatively describe organizational culture and employee satisfaction, and further to empirically explore the relationship between them.

This paper is organized as follows. After this part of introduction, Section 2 firstly gives a brief literature review about organizational culture and employee satisfaction, and then explains the empirical approach used in this research.

Manuscript received January 11, 2013; revised February 20, 2013.

Xiaoxia Zhang is with the School of Foreign Languages, Shanxi University, Taiyuan, CO 030006, P. R. China.

Bing Li is with the School of Economics and Business Administration, Shanxi University, Taiyuan, CO 030006, P. R. China. He is the corresponding author (e-mail: libingsxu@sxu.edu.cn).
Section 3 shows the sample data and describes the analysis results of the studied firm. Section 4 has further discussions on the results by linking the firm's specific situation. Section 5 concludes this paper with limitations and future work.

\section{LITERATURE REVIEW}

Organizational culture is defined as "the set of shared, taken-for-granted implicit assumptions that a group holds and that determines how it perceives, thinks about, and reacts to its various environments" [1]. Organizational culture shows the basic and radical characteristics of an organization. Thus it can become a source of sustainable competitive advantage if that culture is valuable, rare, and imperfectly imitable [2]. Organizational culture can create values since it can simplify information processing, decrease the supervision cost and smooth the bargaining between employees [3].

Organizational culture is related to effectiveness indicated by some important organizational outcomes [4], [5]. Denison and Mishra (1995) measured the organizational culture from four traits: involvement, consistency, adaptability and mission; effectiveness was measured by subjective and objective items. These items were mostly related to financial outcomes, except one subjective item - employee satisfaction [5].

Organizational culture has much more influences on organizational performance by impacting the psychological states of individual employees, working groups and even the whole organization. Actually this complies with the paradigm shift to humanism in business and psychological insights should become the basis for management [6]. Researchers have studied some psychological measures such as job satisfaction [7]-[9], organizational commitment [10]-[12], and psychological empowerment [13]. This research focuses on employee satisfaction and its relationship with organizational culture, especially for the case of a Chinese family firm.

Employee satisfaction is defined as "a pleasurable or positive emotional state" that is "a function of the perceived relationship between what one wants from a job and what one perceives it is offering" [14], [15]. Researchers have made some studies about this psychological factor and its relationship with organizational culture. Denison and Mishra (1995) found the relationship between culture traits and employee satisfaction [5]. Fey and Denison (2003) applied their study further to Russian cases [16]. Lund (2003) made an empirical study of the impact of organizational culture types on job satisfaction in a survey of marketing professionals in the American firms [17]. 


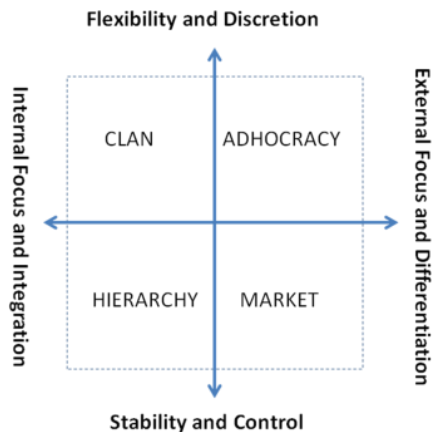

Fig. 1. The Competing values framework (Cameron and Quinn, 2006)

This research uses an empirical approach to explore the relationship between organizational culture and employee satisfaction. The Cameron and Quinn's Organizational Culture Assessment Instrument (OCAI) is employed to measure organizational culture of the studied firm [18].

The OCAI scale is based on the competing values framework (CVF), which was developed initially from research conducted on the major indicators of effective organizations [18]. In the CVF, the organizational culture can be divided into four typical culture types by vertical and horizontal axes, illustrated in Fig. 1. According to the distinguished characteristics of each cultural type, they are labeled as clan, adhocracy, market, and hierarchy. Actually this framework and the derived culture types have combined much work conducted by previous researchers [18]. In the scale of OCAI, by scoring each culture type under the six cultural aspects (we call dimensions in this paper) - dominant characteristics (D1), organizational leadership (D2), management of employees (D3), organization glue (D4), strategic emphases (D5), criteria of success (D6) - the average scores of each culture type can be calculated. The culture profile of the organization can be plotted in a radar graph. The measurement of organizational culture in this paper uses the OCAI scale at the individual level, that is, to ask each involved employee to fill the OCAI scale.

Employee satisfaction is measured by using Minnesota Satisfaction Questionnaire (MSQ). Although it is designed by Weiss et.al in 1967 [9], this scale is still used by many researchers [8]. The MSQ scale is a five-point Likert scale, containing 20 items and each item is scored from 1 to 5 (very dissatisfied, dissatisfied, neither satisfied nor dissatisfied, satisfied, very satisfied). Then the organizational culture and employee satisfaction can be quantitatively described and the relationship can be further investigated by statistical analyses The results can provide some decision support for the managers to accordingly change their organizational culture to improve employee satisfaction.

By comparing with previous studies of organizational culture and employee satisfaction, this research attempts to make a further progress by focusing on the psychological perception of the individual employees and exploring the relationship under the specific situation of a Chinese family firm.

\section{DATA AND ANALYSES}

This research studied a family-owned firm located in
Shanxi province, China. This firm belonged to the coal industry and it was one of the largest firms in its surrounding area. The technique of convenience sampling is used and the survey data are selected by two ways. Altogether 200 questionnaires were handed out. 75 questionnaires were handed out at the end of a meeting for managers (most of them are middle-level or bottom-line managers) and were collected after the respondents completed the questionnaires in the meeting room. The rest of questionnaires (125) were handed out to different departments of the firm - including finance, production and sales - and were collected the day after. Out of the 200 questionnaires, 165 (82.5\%) were returned and $122(61 \%)$ were fully and correctly completed.

The sample (122) contained $87(71.3 \%)$ male employees and $35(28.7 \%)$ female employees. The age structure is as follows: $51(41.8 \%)$ are under the age of 30 years; $46(37.7 \%)$ are between 31 and 45 years old; $25(20.5 \%)$ are above 45 years. The education structure is: $11(9 \%)$ only received the education of junior high school; senior high school, 49 (40.2\%); junior college, 41 (33.6\%); college and above, 21 $(17.2 \%)$. The number of top or middle managers is 19 $(15.6 \%)$; the line managers amount to 40 (32.8\%). The employees who have worked in this firm less than 3 years amount to $50(41.0 \%)$; from 3 to 5 years, 18 (14.8\%); more than 5 years, $54(44.3 \%)$.

\section{A. Organizational Culture Analysis}

From the survey data in OCAI scale, the organizational culture of the firm can be quantitatively described and analyzed as follows.

Reliability of Culture Type. Table I shows the result of reliability analysis of culture types. The reliability of three culture types is good $(0.8 \sim 0.9)$. The Market culture is questionable $(0.6 \sim 0.7)$, but close to acceptable $(0.7 \sim 0.8)$ and above poor level $(0.5 \sim 0.6)$. Basically, the reliability result can satisfy the requirement for social investigation.

Culture Type and Strength. Table II lists the scores of each culture type by averaging the 122 employees' evaluation. The culture profile can be plotted in the competing values framework, shown in Fig. 2. The culture types of clan and hierarchy are strong while the adhocracy and market are weak. Table II and Fig. 2 show that the clan culture is the strongest one in this firm, followed by the hierarchy culture, which is also strong. The adhocracy and market are weak, with small difference between them.

Culture Congruence. In OCAI scale, six cultural dimensions (aspects) are assessed by the employees, and for each dimension four culture types are given points with the restriction that the summary of four types is 100 points. Similar with the profile of organizational culture, the profile of each cultural dimension is plotted in Fig. 3. For simplicity, the axes and four cultural types are omitted. From Table III and Fig. 3, it can be shown that the clan culture is the strongest culture in D1, D3, D4 and D6; the hierarchy culture is the strongest culture in D2 and D5; the adhocracy and market cultures are weak in nearly all the dimensions except for that the market culture is emphasized inD3. By comparing means in the way of pair-samples t-test in SPSS, further statistical analysis is shown in Table IV. For the clan culture, at the 0.01 level of significance, no dimension has difference, 
which provides statistical evidence of the strong congruence. At the 0.05 level, only D3 and D6 show significant difference from

D1. For the hierarchy culture, differences are significant between D1 and other dimensions except D3, which shows weak congruence. The adhocracy and market cultures show

TABLE I: RELIABILITY OF CULTURE TYPE

\begin{tabular}{cr}
\hline \hline Culture Type & Cronbach's Alpha \\
\hline Clan & .859 \\
Adhocracy & .814 \\
Market & .675 \\
Hierarchy & .851 \\
\hline \hline
\end{tabular}

TABLE II: MEANS OF CULTURE TYPE

\begin{tabular}{ccc}
\hline \hline Culture Type & $\mathrm{M}$ & $\mathrm{N}$ \\
\hline Clan & 31.79 & 122 \\
Adhocracy & 19.20 & 122 \\
Market & 19.81 & 122 \\
Hierarchy & 29.20 & 122 \\
\hline
\end{tabular}

the mediate congruence between clan and hierarchy. In summary, 8 out of $20 \mathrm{t}$ values are significant at the level of 0.01 and 3 more $t$ values are significant at the level of 0.05 , meaning

TABLE III: MEANS OF SIX CULTURAL DIMENSIONS

\begin{tabular}{|c|c|c|c|c|c|c|}
\hline $\begin{array}{l}\text { Dimension } \\
\text { Type }\end{array}$ & $\begin{array}{c}\text { D1 } \\
\text { Dominant } \\
\text { Characteristics }\end{array}$ & $\begin{array}{c}\text { D2 } \\
\text { Organizational } \\
\text { Leadership }\end{array}$ & $\begin{array}{c}\text { D3 } \\
\text { Management } \\
\text { of Employees }\end{array}$ & $\begin{array}{c}\text { D4 } \\
\text { Organization } \\
\text { Glue }\end{array}$ & $\begin{array}{c}\text { D5 } \\
\text { Strategic } \\
\text { Emphases }\end{array}$ & $\begin{array}{c}\text { D6 } \\
\text { Criteria } \\
\text { of Success }\end{array}$ \\
\hline Clan & 30.61 & 28.32 & 34.93 & 31.93 & 30.38 & 34.55 \\
\hline Adhocracy & 21.39 & 20.41 & 15.15 & 17.70 & 22.11 & 18.44 \\
\hline Market & 22.42 & 19.92 & 25.04 & 19.47 & 15.55 & 16.48 \\
\hline Hierarchy & 25.57 & 31.35 & 24.88 & 30.90 & 31.97 & 30.53 \\
\hline
\end{tabular}

D1-Dominant Characteristics

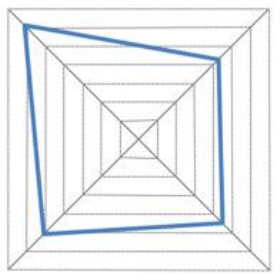

D4-Organization Glue

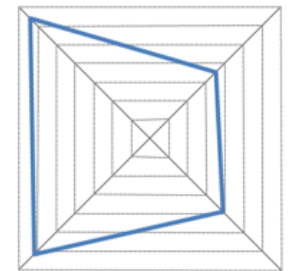

D2-Organizational Leadership

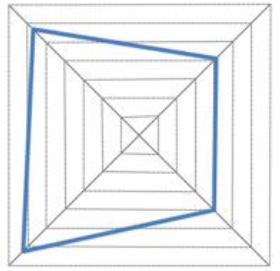

D5-Strategic Emphases

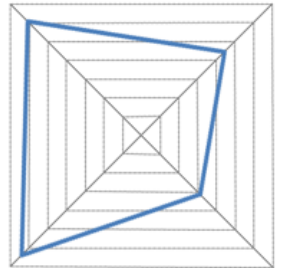

Flexibility and Discretion

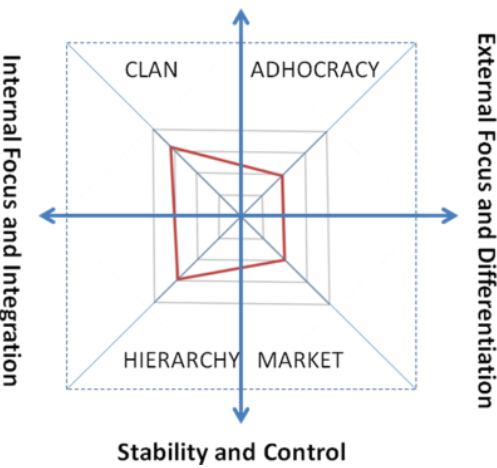

Fig. 2. The profile of the organizational culture 


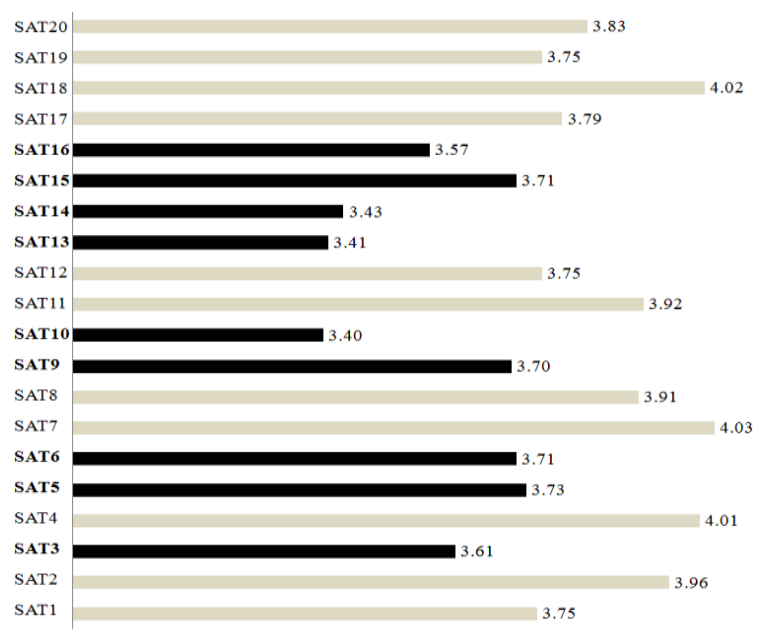

Fig. 4. The means of employee satisfaction items

TABLE V: CORRELATIONS BETWEEN ITEM SATISFACTION AND Culture Type $(\mathrm{N}=122)$

\begin{tabular}{|c|c|c|c|c|c|}
\hline & & Clan & Adhocracy & Market & Hierarchy \\
\hline \multirow{3}{*}{ SAT2 } & Pearson & & -.208 & & .196 \\
\hline & Correlation & & & & \\
\hline & Sig. (2-tailed) & & .021 & & .031 \\
\hline \multirow[t]{3}{*}{ SAT3 } & Pearson & & & & .179 \\
\hline & Correlation & & & & \\
\hline & Sig. (2-tailed) & & & & .049 \\
\hline \multirow[t]{2}{*}{ SAT13 } & $\begin{array}{l}\text { Pearson } \\
\text { Correlation }\end{array}$ & & & -.192 & \\
\hline & Sig. (2-tailed) & & & .034 & \\
\hline \multirow[t]{2}{*}{ SAT19 } & $\begin{array}{l}\text { Pearson } \\
\text { Correlation }\end{array}$ & & & & -.178 \\
\hline & Sig. (2-tailed) & & & & .049 \\
\hline
\end{tabular}

the significant difference between these culture scores. Obviously, hierarchy culture shows the worst congruence that should be concerned by managers.

\section{B. Employee Satisfaction Analysis}

Employee satisfaction is an indicator of organizational effectiveness in this paper. The MSQ scale is used to measure this psychological variable. The coefficient of Cronbach's Alpha is 0.85 , showing a good reliability. The average scores of twenty items of satisfaction are illustrated in Fig. 4. The dark bars show the nine items of satisfaction, the scores of which are below the overall satisfaction $(3.75)$ - the mean of the 20 satisfaction items. The nine items with lower level of satisfaction are actually what the mangers should pay more attention to and find a way to improve.

\section{The Relationship between Organizational Culture and} Employee Satisfaction

Following the above statistical description of organizational culture and employee satisfaction, this part explores the relationship between them. The OCAI scale provides two levels of cultural data: the top level is the overall organizational culture that is represented by the score distribution of four basic culture types - clan, adhocracy, market and hierarchy, symbolized as OC4; the bottom level is the four cultural score distribution under six cultural dimensions, corresponding to the 24 items in the OCAI scale, symbolized as OC24. Similarly, the MSQ scale can provide two levels of satisfaction: the overall satisfaction represents the average score of all the satisfaction items, symbolized as SAT; the item satisfaction corresponds with the 20 items in the MSQ scale, symbolized as SAT20. Thus, the relationship between organizational culture and employee satisfaction can be statistically explored by analyses of the correlations of SAT-OC4, SAT-OC24, SAT20-OC4, and SAT20-OC24. SAT-OC4 means the correlation between SAT and OC4.

TABLE VI: CORRELATIONS BETWEEN ITEM SATISFACTION AND CULTURAL DIMENSIONS

\begin{tabular}{|c|c|c|c|c|c|c|c|c|c|c|c|c|c|}
\hline & & \multirow{2}{*}{$\begin{array}{c}\text { D1 } \\
\text { Market }\end{array}$} & \multicolumn{3}{|c|}{ D2 } & \multicolumn{2}{|c|}{ D3 } & \multicolumn{2}{|c|}{ D4 } & \multicolumn{2}{|c|}{ D5 } & \multicolumn{2}{|c|}{ D6 } \\
\hline & & & Clan & Adhoc & Hier & Clan & Adhoc & Adhoc & Hier & Clan & Market & Market & Hier \\
\hline \multirow{2}{*}{ SAT1 } & Corr. & & & & & & -.179 & & & & & & \\
\hline & Sig. & & & & & & .049 & & & & & & \\
\hline \multirow{2}{*}{ SAT2 } & Corr. & -.200 & & -.198 & .184 & & -.299 & -.252 & .235 & & & & .201 \\
\hline & Sig. & .027 & & .029 & .042 & & .001 & .005 & .009 & & & & .026 \\
\hline \multirow{2}{*}{ SAT3 } & Corr. & & & & & & -.180 & & & & & -.187 & .224 \\
\hline & Sig. & & & & & & .047 & & & & & .039 & .013 \\
\hline SAT4 & $\begin{array}{l}\text { Corr. } \\
\text { Sio }\end{array}$ & & & & & & $\begin{array}{r}-.278 \\
002\end{array}$ & & & & & & \\
\hline \multirow{2}{*}{ SAT6 } & Corr. & -.232 & & & & .189 & & & & & & & \\
\hline & Sig. & .010 & & & & .037 & & & & & & & \\
\hline \multirow{2}{*}{ SAT7 } & Corr. & & & & & .224 & & & & & & & \\
\hline & Sig. & & & & & .013 & & & & & & & \\
\hline \multirow{2}{*}{ SAT10 } & Corr. & & & & & & & & .192 & & & & \\
\hline & Sig. & & & & & & & & .034 & & & & \\
\hline \multirow{2}{*}{ SAT13 } & Corr. & & .181 & & & & & & & & & -.211 & \\
\hline & Sig. & & .046 & & & & & & & & & .020 & \\
\hline \multirow{2}{*}{ SAT15 } & Corr. & & & & & & & & & & -.227 & & \\
\hline & Sig. & & & & & & & & & & .012 & & \\
\hline \multirow{2}{*}{ SAT16 } & Corr. & -.189 & & & & & & & & & & & \\
\hline & Sig. & .037 & & & & & & & & & & & \\
\hline \multirow{2}{*}{ SAT17 } & Corr. & & & & & & & & -.232 & & & & \\
\hline & Sig. & & & & & & & & .010 & & & & \\
\hline \multirow{2}{*}{ SAT18 } & Corr. & & & & & & & & & .223 & & & \\
\hline & Sig. & & & & & & & & & .014 & & & \\
\hline \multirow{2}{*}{ SAT19 } & Corr. & & & & & & & & -.186 & & & & \\
\hline & Sig. & & & & & & & & .040 & & & & \\
\hline
\end{tabular}


Overall Employee Satisfaction and Organizational Culture. The analysis result of SAT-OC4 shows that the relationship between overall employee satisfaction and four culture types is not obvious. Further analysis of SAT-OC24 shows that the SAT is only negatively related to adhocracy culture under the dimension of D3 (Management of Employees) - the probability of significance is 0.03 and the correlation coefficient is -0.197 .

Item Employee Satisfaction and Organizational Culture. The result of SAT20-OC4 is shown in Table V. For compactness, the correlations are listed when the significance level is below 0.05. By linking the analysis results (negatively or positively relation) with the firm's situation, it is possible to provide decision support for the culture management. For example, the item of SAT13 - My pay and the amount of work I do - is negatively related to the market culture, which shows that this item satisfaction can possibly be improved by weakening the market culture.

\begin{tabular}{|c|c|c|c|c|}
\hline & \multicolumn{2}{|c|}{ Group 1} & \multicolumn{2}{|c|}{ Group 2} \\
\hline & M & SD & M & SD \\
\hline \multirow[t]{2}{*}{ SAT } & 4.077 & 0.228 & 3.499 & 0.220 \\
\hline & 33.41 & 12.25 & 30.53 & 15.14 \\
\hline \multirow[t]{2}{*}{ Clan } & 2 & 3 & 9 & 4 \\
\hline & 18.04 & 10.23 & 20.09 & \\
\hline \multirow[t]{2}{*}{ Adhocracy } & 5 & 5 & 0 & 7.624 \\
\hline & 18.04 & & 21.17 & \\
\hline \multirow[t]{2}{*}{ Market } & 1 & 9.019 & 1 & 7.344 \\
\hline & 30.50 & 12.63 & 28.20 & 14.99 \\
\hline Hierarchy & 4 & 5 & 1 & 6 \\
\hline $\mathrm{N}$ & \multicolumn{2}{|c|}{53} & \multicolumn{2}{|c|}{69} \\
\hline
\end{tabular}

TABLE VIII: ANALYSIS OF OVERALL SATISFACTION AND CULTURAL DIMENSIONS

\begin{tabular}{rr|rr|rrr}
\hline \hline & & \multicolumn{2}{|c|}{ Group 1 } & $(\mathrm{N}=53)$ & \multicolumn{3}{|c}{ Group 2 } & \multicolumn{2}{c}{$(\mathrm{N}=69)$} \\
& & D5 & D6 & D1 & D4 & D5 \\
& & Market & Adhocracy & Hierarchy & Clan & Market \\
\hline \multirow{2}{*}{ SAT } & Corr. & .272 & .288 & -.284 & .261 & -.293 \\
& Sig. & .049 & .036 & .018 & .030 & .015 \\
\hline \hline
\end{tabular}

Table VI shows the analysis result of SAT20-OC24. The correlations are selected only when the significance level is below 0.05 . Under each dimension, four basic culture types are evaluated and the culture types without significant correlations (the level of 0.05 ) are omitted. Out of 480 $(20 \times 24)$ correlations, 23 ones are significant at the level of 0.05 . This analysis provides more detailed investigations on the item satisfaction and culture type under each dimension. For example SAT-13, under the dimension of D2 (Organizational Leadership), this item satisfaction is positively related to the clan culture, which means that it can help to improve this item satisfaction by strengthening the clan culture in the aspect of organizational leadership. Similarly, under the dimension of D6 (Criteria of Success), the significant and negative relationship shows that weakening the market culture under this dimension can help to improve this item satisfaction. The other correlations can be examined in the similar way. But it should be remembered that it is necessary to always link the statistical analyses with the organization's situations and management practices, and cautiously examine the appropriateness of the explanation.

Classification of Employee Satisfaction. According to the employees' scores of item satisfaction, the employees can be divided into two groups by way of K-means cluster analysis in SPSS. Table VII shows the two groups: Group 1 has a higher mean of satisfaction while Group 2 has a lower one. Although the two stronger culture types are clan and hierarchy, Group 1 shows higher means and lower standard deviations in these two culture types. For the culture types of adhocracy and market, Group 2 shows higher means and lower standard deviations. The analysis shows one possible way to improve satisfaction - to strengthen clan and hierarchy culture and to weaken adhocracy and market culture.

Furthermore, Group1 and Group 2 can also be analyzed with the correlations of SAT-OC4, SAT-OC24, SAT20-OC4, and SAT20-OC24. Table VIII shows the SAT-OC24 analysis for these two groups. The significant correlations are different in the two groups. Especially for the dimension of D5 (Strategic Emphases), the market culture shows opposite effects: for Group 1 market culture is positively related to satisfaction while for Group 2 this culture is negatively related to satisfaction. Further analysis of SAT20-OC24 shows 25 significant correlations in Group 1 and 31 ones in Group 2 (similar table format with Table VI; not shown here for space saving). By linking these analyses with organizational context, it is helpful to find some hints to improve satisfaction by culture changes - strengthen or weakening some culture types in a specific organizational aspect.

\section{DISCUSSION}

The preceding part shows the statistical analysis results and now this section makes some detained explanations by combining the above analyses with the investigated firm's context as a Chinese family firm.

Culture Profile. Fig. 2 shows the two stronger culture types - clan and hierarchy. A clan is similar to a family-type organization and "typical characteristics of clan-type firms were teamwork, employee involvement and corporate commitment to employees" [18]. This clan feature of family firms has been confirmed by many researchers $[19,20]$. In family firms, commitment, harmony, long-term orientation and customer service are culture values generalized by Vallejo [21] and these values are consistent with the clan culture.

Since the founder of this family-owned company is still in charge of the firm's board committee and some members of the family are taking important positions in this firm, the clan culture continues to be strong. This firm has the organizational characteristics that focus on "internal maintenance with flexibility, concern for people, and sensitivity to customers" [18].

Following the clan culture, the hierarchy culture is the second strongest culture in this firm. This firm was initially founded in the year of 1990 and has developed for more than twenty years. Till the middle of 2012, the number of employees was about 1700. As a large manufacturing company in coal industry, the control and stability are still needed and thus the hierarchy culture is also prominent. 
Besides, the firm is located in the central China where the society and economy are underdeveloped, and the hierarchy culture can still work efficiently. This is in line with the power distance dimension for Chinese national culture [22].

Culture Congruence. This concept means that "various aspects of an organization's culture are aligned" and "the same culture types are emphasized in various parts of the organization" [18]. These aspects are called dimensions in this paper. Fig. 3 shows that culture types are nearly consistent in most dimensions. Further t-test analysis shows that the clan culture is the most congruent among the four culture types while the hierarchy culture is the most incongruent. The clan culture is emphasized in various parts while the hierarchy culture is varied in different organizational divisions. Linking the firm's situation, it is proper to assume that the organizational culture was initially dominated by the clan culture, and the hierarchy culture was increasingly strengthened with the firm's development - this process is consistent with the organizational life cycle [23]. Thus the clan culture is congruent while the hierarchy culture is incongruent.

Employee Satisfaction. This measure is used to indicate organizational effectiveness in this paper. Fig. 4 shows employee satisfaction in the firm. The nine items with lower level of satisfaction are necessary for managers to take action to improve. Organizational culture is a predictor of employee satisfaction [7, 17]. By exploring the relationship between organizational culture and employee satisfaction, it is possible to find a way to improve employee satisfaction by making cultural changes.

Relationship between organizational culture and employee satisfaction. As explained in previous parts, correlation analyses such as SAT-OC4, SAT-OC24, SAT20-OC4, and SAT20-OC24 are conducted. In the general level of SAT-OC4, the analysis result shows no significant relationship between organizational culture and employee satisfaction. This finding is different from the previous research result that satisfaction is positively related to clan and adhocracy culture [17]. This can be explained by the different occupations of the investigated employees or respondents since Lund (2003) surveyed in marketing professionals. This relationship could vary with different firms or industries. But it seems appropriate that no significant relationship was found in the investigated firm at the general level analysis of SAT-OC4. Since four cultures comprise an organizational culture in Cameron and Quinn's framework, any firm has a combination of these four cultures. The overall culture will evolve with the development of the organization. Neutrally speaking, no good or bad is organizational culture, but fit or not. This analysis result for SAT-OC4 can be explained as above but this explanation should be tested by more surveys in various firms across various industries and geographies.

With further analyses, the significant correlations come out. It can be easily understood that specific item satisfaction is easily related to a specific culture type especially in a specific aspect of organization. Thus the analysis of SAT20-OC24 shows more significant correlations, meaning significant relationships between item satisfaction and culture types under a specific culture dimension. Cluster analysis of employee satisfaction shows the difference of cultural perception between higher and lower satisfaction groups.

Regretfully, the further analyses can provide only specific findings for the investigated firm and thus it is difficult to generalize the research results. But as a side product, this research actually provides one way to diagnose organizational culture by linking with employee satisfaction and to find definite suggestions to improve satisfaction by making culture changes. This paper also illustrates the complex features of organizational culture.

\section{CONCLUSION}

This research makes an empirical study of organizational culture and explores the relationship between organizational culture and employee satisfaction under the specific situation of a Chinese family-owned firm. Since only specific relationships between organizational culture and employee satisfaction were found, the research results are not ready to be generalized or reach a general conclusion. But as the previous part of discussions explained, it can still provide a way to empirically diagnose organizational culture and to make some suggestions for managers to improve effectiveness by changing organizational culture. Besides, this paper uses employee satisfaction as an indicator of effectiveness, and it is viable to employ other indicators such as organizational commitment and psychological empowerment. These psychological indicators are more important for management of employees in the knowledge-based economies.

This research has some limitations and future work can be done. Although we had a two-day's visit to this investigated firm and had some informal talks with some employees, this research was conducted mostly in a quantitative way. It will be better to continue some qualitative research and make comparison between qualitative and quantitative results. A second limitation is the cross section study. It is meaningful to take a longitudinal study and can thus explore some dynamic features of organizational culture and its relationship with effectiveness. A third limitation comes from the sample size of survey data. It can provide more evidence to investigate firms across industries and geographies. Finally, concerning more about individual personalities such as gender, age and education can possibly provide fruitful results to support managerial decisions on human resource management.

\section{ACKNOWLEDGEMENTS}

This work was supported in part by the Humanities and Social Science Fund of Shanxi University (No.1009011). The authors also wish to thank the three graduates for their work in this research, Xin Zhao, Yuan Liu and Ruipeng Ning. The anonymous referees are also appreciated for their helpful comments and suggestions.

\section{REFERENCES}

[1] E. H. Schein, "Culture: The Missing Concept in Organization Studies," Administrative Science Quarterly, vol. 41, no. 2, 40th Anniversary Issue, pp. 229-240, 1996. 
[2] J. B. Barney, "Organizational Culture: Can It Be a Source of Sustaine Competitive Advantage?" The Academy of Management Review, vol. 11, no. 3, pp. 656-665, July, 1986.

[3] D. Besanko, D. Dranove, and M. Shanley, The Economics of Strategy, John Wiley, 1996.

[4] D. R. Denison, "Bringing Corporate Culture to the Bottom Line," Organizational Dynamics, vol. 13, no. 2, pp. 4-22, 1984.

[5] D. R. Denison and A. K. Mishra, "Toward a Theory of Organizational Culture and Effectiveness," Organization Science, vol. 6, no. 2, pp. 204-223, 1995

[6] M. A. Pirson and P. R. Lawrence, "Humanism in Business - Towards a Paradigm Shift?" Journal of Business Ethics, vol. 93, pp. 553-565, 2010.

[7] V. Bellou, "Organizational culture as a predictor of job satisfaction: the role of gender and age," Career Development International, vol. 15, no.1, pp. 4-19, 2010.

[8] T. Lim, "Relationships among organizational commitment, job satisfaction, and learning organization culture in one Korean private organization," Asia Pacific Education Review, vol. 11, pp. 311-320, 2010.

[9] D. J. Weiss, R. V. Dawis, G. W. England, and L. H. Lofquist, Manual for the Minnesota Satisfaction Questionnaire, Minneapolis, MN: Work Adjustment Project of the University of Minnesota, 1967.

[10] J. P. Meyer and N. J. Allen, "A three-component conceptualization of organizational commitment," Human Resource Management Review, vol. 1, pp. 61-89, 1991.

[11] J. P. Meyer, D. J. Stanley, L. Herscovitch, and L. Topolnytsky, "Affective, continuance and normative commitment to the organization: A meta-analysis of antecedents, correlates and consequences," Journal of Vocational Behavior, vol. 61, pp. 20-52, 2002.

[12] J. P. Meyer, L. J. Stanley, and N. M. Parfyonova, "Employee commitment in context: The nature and implications of commitmen profiles," Journal of Vocational Behavior, vol. 80, pp. 1-16, 2012.

[13] G. M. Spreitzer, "Psychological empowerment in the workplace: Dimensions, measurement, and validation," Academy of Management Journal, vol. 38, no. 5, pp. 1442-1465, 1995.

[14] E. A. Locke, The nature and causes of job satisfaction, Chicago: Rand McNally, 1976.

[15] G. Wang and P. D. Lee, "Psychological Empowerment and Job Satisfaction - An Analysis of Interactive Effects," Group \& Organization Management, vol. 34, no. 3, pp. 271-296, 2009.
[16] C. F. Fey and D. R. Denison, "Organizational Culture and Effectiveness: Can American Theory Be Applied in Russia?" Organization Science, vol. 14, no. 6, pp. 686-706, 2003

[17] B. Lund, "Organizational culture and job satisfaction," Journal of Business and Industrial Marketing, vol. 18, no. 3, pp. 219-36, 2003.

[18] K. S. Cameron and R. E. Quinn, Diagnosing and Changing Organizational Culture: Based on the Competing Values Framework, Revised edition, The Jossey-Bass business \& management series, 2006.

[19] R. Anderson and D. Reeb, "Founding family ownership and firm performance: Evidence from the S\&P 500," Journal of Finance, vol. 58, pp. 1301-1329, 2003

[20] J. Lee, "Family firm performance: Further evidence," Family Business Review, vol. 19, pp. 103-114, 2006.

[21] M. C. Vallejo, "A model to study the organizational culture of the family firm,” Small Business Economics, vol. 36, pp. 47-64, 2011.

[22] G. Hofstede and G. J. Hofstede, Cultures and Organizations: Software of the Mind, McGraw-Hill, New York, 2005.

[23] R. E. Quinn and K. S. Cameron, "Organizational Life Cycles and Shifting Criteria of Effectiveness: Some Preliminary Evidence," Management Science, vol. 29, no. 1, pp. 33-51, 1983.

Xiaoxia Zhang is a Ph.D. candidate in the Graduate School of Economics in Rikkyo University, Japan. She is also a lecturer in the School of Foreign Languages, Shanxi University, China. Her master degree in Arts (2005) was from Shanxi University and master degree in Economics (2008) was from Rikkyo University. Her present research focuses on organizational culture, cross culture management and culture intelligence.

Bing $\mathbf{L i}$ is a lecturer in the School of Economics and Business Administration, Shanxi University, China. He got his doctor degree (2008) in Industrial Engineering and Management in Tokyo Institute of Technology, Japan. His master degree (2003) and bachelor degree (2000) was from Xi'an Jiaotong University, China. His research interests are organizational culture, financial econometrics, information systems and e-business. 